\title{
GENEROSITY LINKED TO SPIRITUALITY, RESILIENCE AND PSYCHOLOGICAL WELL-BEING AMONG YOUTH: THE PSYCHOLOGY OF GOODNESS
}

\author{
Najma Iqbal Malik ${ }^{1 *}$, Shahida Perveen ${ }^{2}$, Mehr Mohsin Raza ${ }^{3}$ \\ ${ }^{1 * 2}$ Department of Psychology, University of Sargodha, Pakistan; ${ }^{3}$ Department of Education, University of Sargodha, \\ Pakistan. \\ Email: ${ }^{1 *}$ najmamalik@gmail.com, ${ }^{2}$ shahidaperveen11@gmail.com, ${ }^{3}$ mohsinuos35@hotmail.com
}

Article History: Received on $11^{\text {th }}$ January 2021, Revised on $14^{\text {th }}$ March 2021, Published on $19^{\text {th }}$ March 2021

\begin{abstract}
Purpose of the study: This exploration was intended to check the link of generosity upon resilience, spirituality, and psychological adjustment among youth.

Methodology: Purposive sample of volunteer Youth workers $(\mathrm{N}=175)$ of welfare and charity organizations from three major Pakistani cities (age range 19 to 28 years both male and female) were part of the study. International Personality Item Pool scale; sub-constructs of Generosity and Spirituality from Values in Action scale, Psychological Well-Being (PWB), and the Resilience Scale (CD-RISC) were used to measure concepts in the current exploration. Data were analyzed using SPSS 23 version. Pearson correlation was used to check correlation among variables. The prediction was checked through linear regression. Lastly, an independent sample t-test was used to analyze demographics.
\end{abstract}

Main Findings: Significant positive relationship of generosity with spirituality, resilience, and psychological well-being among youth was found. Spirituality was positively predicted by generosity; whereas psychological wellbeing was positively predicted by resilience. Female youth had high generosity and was more resilient but spirituality and psychological well-being were the same across genders. Youth from joint families was more generous and resilient than those from nuclear families.

Implications of this study: Study findings have sound practical implications for policymakers, community activists, and social / health psychologists to understand the generosity phenomena and how it can be vital for building a sustainable and progressive community. Suggestions for future researchers along with present study limitations have also been discussed.

Novelty/Originality of this study: This is empirical research and all the data is based upon natural human behavior without any manipulation.

Keywords: Generosity, Spirituality, Resilience, Psychological Well-being, Youth.

\section{INTRODUCTION}

As human beings, and as social animals, people prefer to live in environments that support and nurtured them and can thrive with others, there exists a strong responsibility towards the well-being of society as a whole, and as humans, they are fundamentally designed to live this way.

In the evolutionary biological study of cooperation, it is widely accepted that humans cooperate in a wide variety of ways and on large scales (Townsend, Aktipis, Balliet \& Cronk, 2020). The human being is often generous, cooperative, and trusting within their groups. Being charitable on one hand is "a nice thing to do" whereas, on other hand, it is compulsory for human survival, as well as for our well-being globally. It is also true that being charitable and generous towards others is a spiritual asset and in this way, he/she can contribute to community building. Generosity had been defined as the characteristics of being understanding and kind, the concept to share valuable things as well as being selfless. Generosity is considered a spiritual value as well as a spiritual practice. Generosity is a universal concept hence it is part of religious teachings in all major religions in the world. In the Islamic religion, generosity is one of the five pillars. Researchers have found that generosity / prosocial behavior has been linked with one's religion and more religious people tend to be more generous to be good in front of GOD (Sablosky, 2014). It was also argued that one's religious experiences, participation, and belief function to promote prosocial behavior and fosters one's spiritual wellbeing. Similarly, James and colleagues (2015) found that having sense of purpose or more coherent spirituality was directly related to generosity (James, Anthony \& Fine, 2015). Some researchers highlighted the emphasis of religious morality and noted the Golden Rule, "Do unto others as you would have others do unto you," as a component among major religions (Wilson, 1956). Whereas others explored that every religion mainly advocates cooperation and helping behavior within in-groups among cultures (Ruffle \& Sosis, 2006) in place of supporting an indiscriminate disposition to prosocial behavior. A consistent body of previous literature mentioned that being religious had a positive impact on prosocial behavior, whereas had a negative impact on antisocial/criminal behavior (Durrant \& Poppelwell, 2017).

With advances in research, resilience is now understood as involving dynamic multilevel systemic processes over time. The response to a disaster by communities and larger systems can make a difference for individual and family wellbeing and resilience (Walsh, 2020). Recently in the era of global issues related to humanity decline and human 
sufferings huge importance has been given to mental health, religion, spirituality, and resiliency in the present decade. Although, all researches do not comply (e.g., Laurent et al., 2013; King, et. al., 2013) and no cause and effect relation was reported (Miller \& Thoreson, 2003), yet prospective studies with cross-sectional designs, on average, done among the general community as well as clinical samples discovered the link between spiritual and religious beliefs and their application to resiliency and mental well-being throughout the life (Koenig, McCullough \& Larson 2001; Bonelli \& Koenig, 2013; Sternthal, Williams, Muscik, \& Buck, 2010), improved perception about the life's quality (Lucchetti et al., 2012), reduction in distress caused as a result of negative incidents in life (Koenig \& Vaillant, 2009; McCaffrey, Eisenbert, Legedza, Davis, \& Phillips, 2004), as well as improved coping /mental health outcomes after traumatic experiences (McIntosh, Poulin, Silver, \& Holman, 2011; Connor, Davidson, \& Lee, 2003; Ahrens, Abeling, Ahmad, \& Hinman, 2010). The Walsh family resilience framework identified nine key processes-facilitative beliefs and practices - in three domains of family functioning: family belief systems, family organizational processes, and communication/ problem-solving processes (Walsh, 2020).

We are relational beings. Recognition of our essential interdependence is vital for our well-being and resilience. In turning to others for help, we can pay it back and pay it forward (Walsh, 2020). Although these along with other researches from the last two decades had mentioned an overall positive impact of spiritual and religious exercises on mental health (Bonelli \& Koenig, 2013). Researches did by Van Dyke, et, al. (2009), Koenig (2012), and Choudhry, et al., (2018) found that religious values and generosity played a vital role in enhancing resiliency and mental well-being among troubled youth. Research also found that among youth interpersonal generosity is a valuable personal trait that has been expressed through social relationships and focuses on giving personal good, such as attention, and found to be strongly linked with their mental and social development as well (Smith \& Hill, 2009). On the other hand, actionoriented life management strategies as optimization (allocation and refinement of resources), compensation (change of means to maintain the desired functioning), and the person's belief of himself about the execution of required actions to resolve the social situations/contexts (Bandura, 1982, p. 122) are correlated with the judgment that UNESCO-related projects are effective in changing something. Previous literature had also reported that spiritual practices and beliefs along with spiritual commitments result in positive aspects i.e., psychological well-being; improved interpersonal performance and functioning; as well as increased quality of life (Seybold \& Hill, 2001), spiritual orientation towards life may be one of the contributory factors that protect humans against undesirable and maladaptive behaviors (Emmons, $\underline{2000}$ ). Resilience in response to loss and other major disruptions does not mean "just bounce back," quickly rallying and moving on unscathed. Healing and resilience are forged gradually over time (Walsh, 2020).

Regarding gender differences, we find females to be more generous than males (Hasan \& Ejaz, 2018). Shaheen (2016) found that female students scored significantly higher on spirituality in comparison to male students. Moreover, in another study by Vinayak and Judge (2018), girls were found to be more empathetic and resilient than boys. Southwick et. al. (2016) mentioned that a huge amount of literature mentioned that psychological resilience is generally fostered by caregiving / environmental conditions in the time of childhood that are emotionally responsive, loving, reliable, and consistent. This research suggested that, when the environment also gives enough chances to learn challenges and stresses, it will have a "steeling" impact, that aids to promote resilience. Family resilience is fostered by shared beliefs (1) to make meaning of the crisis and challenges; (2) to (re)gain a positive, hopeful outlook that supports active agency, and (3)for transcendence: to rise above suffering and hardship through larger values, spiritual beliefs, and practices, and experiencing transformations in new priorities, a sense of purpose, and deeper bonds (Walsh, 2020).

Keeping in view the above literature, this study focused on the relationship of generosity with spirituality, resilience, and psychological adjustment among youth. Existing literature gives us evidence about the relationship between these variables under study. There exist a correlation between generosity, spirituality, resilience, and psychological wellbeing but very little literature was available in Pakistani culture. So present study was conducted in indigenous settings. Generosity is an important personality trait that plays a vital role in every age group. It affects the behavior of the person directly and is related to spirituality. Resilience is an individual's ability to recover quickly from trauma or difficulty. It is clear from the literature that resilience is related to psychological wellbeing. Therefore cultivating a harmonious and mentally healthy society is much more need of the time to be acted upon the giving principle of Islam which teaches us for helping the needy and the ultimate result is spiritual, mental, and psychological health. The present study was conceived with the objective to saught the relationship between generosity with spirituality, resilience, and psychological adjustment among youth by exploring demographic differentiation (gender, family system). The current study specifically hypothesized i.e.,

H1: There would be a significant positive correlation between generosity, spirituality, resilience, and psychological adjustment among youth.

H2: Generosity would be a significant positive predictor of spirituality, resilience, and psychological adjustment among youth.

H3: Female and male youth would differ in terms of their generosity, spirituality, resilience, and psychological adjustment among youth. 
H4: Youth from the joint family system would have a different level of generosity, spirituality, resilience, and psychological adjustment as compared to youth from the nuclear family system.

\section{METHODOLOGY}

Sample. A sample of 175 youth purposively selected from three major Pakistani cities (Lahore, Faisalabad, and Rawalpindi) inclusive of both male $(n=98)$ and female $(n=77)$ who were volunteer participants of some sort of welfare and charity organizations and had an age of 19 to 24 year $(\mathrm{M}=20.5, \mathrm{SD}=2.89)$ were part of the study. As per study requirements, inclusion criteria were set for the age range of the youth sample similar to as per criteria laid by The United Nations which defines youth as individuals between 15 and 24 years of age. Both urban and rural area youth was part of the sample and the education level of the sample ranges from intermediate (38\%), graduation (35\%), and masters (27\%). Only the youth who was actively involved in welfare and charity work and spends more than 10 hours per week was included as a sample.

\section{Instruments}

International Personality Item Pool-Values in Action (used for sub-constructs of Generosity and Spirituality) (Peterson \& Seligman, 2004). Sub-scales of International Personality Item Pool- Values in Action i.e., Generosity/kindness (10 items) and Spirituality/religiosity (09 items) were used to measure the constructs. The scales were arranged on a 5 point Likert type format ranging the response "Very Inaccurate" was rated as 1, "Moderately Inaccurate" rated as 2, "Neither Inaccurate nor Accurate" rated as 3, "Moderately Accurate" rated as 4, and "Very Accurate" rated as 5. The total score ranges between 10-50 for Generosity and 9 to 45 for spirituality and a higher score means a high value of the construct.

Resilience Scale (Corner-Davidson, 2003). This scale consisted of a total of 25 questions recorded on a 5-point Likert scale where "not true at all" was rated as 0 , "rarely true" rated as 1 , "sometimes true" rated as 2, "often true" rated as 3 , and "true nearly all of the time" rated as 4 . The scale was responded to depending upon the feeling of participants from more than one previous month. The total of scores was between $0-100$, where a high score was meant to be greater resilience.

Psychological Well-Being (PWB, Ryff \& Keyes, 1995). The Ryff Psychological well-being scale comprised of 18 statements, which were recorded on a 6-point Likert scale as follows: "strongly disagree" was rated as 1, "moderately disagree" rated as 2, "slightly disagree" rated as 3, "slightly agree" rated as 4, "moderately agree" rated as 5 and "strongly agree" rated as 6 . Total of the score was between 18 and 108; with higher scores correspond to improved psychological well-being.

Procedure. Following the APA ethical considerations as the first step formal permissions from the institutional research board, followed by the departmental board of studies and permissions from the original authors of the scales were sought to be used in research. Afterward, the purposively selected sample was approached directly by the researcher. The survey was considered to design the present research and a total of 183 respondents were approached who were volunteer participants of some sort of welfare and charity organizations and were elucidated about the aims and objectives of the research. Informed consent was taken for participation in research and confidentiality assurance was also provided. The participants were instructed about the method for filling the questionnaire. The demographic data sheet was also filed by them along with questionnaires. Afterward, cleaning of these forms ended in a total of 175 respondents' data that was made part of study analysis and the rest was discarded as was not properly filled or incomplete.

Data Analysis. The final data of 175 respondents were analyzed with the help of SPSS 23. Psychometric assessment of scales was done through Alpha reliabilities and hypotheses testing was done with the help of Pearson correlation, linear regression, and t-test.

\section{RESULTS/FINDINGS}

Table 1: Pearson Correlation Matrix of All Study Variables for Youth $(\mathrm{N}=175)$

\begin{tabular}{lccllll}
\hline Variables & $\boldsymbol{M}$ & $\boldsymbol{S D}$ & Spirituality & Resilience & PWB & $\boldsymbol{\alpha}$ \\
\hline Generosity & 31.22 & 4.82 & $.87^{* *}$ & $.77^{* *}$ & $.90^{* *}$ & .86 \\
\hline Spirituality & 28.71 & 6.85 & - & $.89^{* *}$ & $.88^{* *}$ & .79 \\
\hline Resilience & 57.50 & 5.24 & - & - & $.89^{* *}$ & .80 \\
\hline PWB & 91.51 & 20.04 & - & - & - & .85 \\
\hline
\end{tabular}

Note. $\mathrm{PWB}=$ Psychological Well-being.

$* * p<.01$.

Table 1 shows that generosity has a significant positive correlation with spirituality, resilience, and psychological wellbeing of youth involved in welfare tasks. 
Table 2: Linear Regression Predicting Spirituality, Resilience, and Psychological wellbeing among youth (N=175)

\begin{tabular}{lllllll}
\hline Model & \multicolumn{2}{c}{ Spirituality } & \multicolumn{2}{c}{ Resilience } & \multicolumn{2}{c}{ Psychological Well-being } \\
\hline & $\beta$ & $\Delta R^{2}$ & $\beta$ & $\Delta R^{2}$ & $\beta$ & $\Delta R^{2}$ \\
\hline Generosity & $.87^{* *}$ & .27 & $.77^{* *}$ & .33 & $.90^{* *}$ & .44 \\
\hline
\end{tabular}

$* * p<.01$.

Table 2 indicates generosity is a significant predictor of spirituality, resilience and psychological well-being at [F (1, $173)=.87, .77, .90, p<.01]$ and explains $27 \%, .33 \%$ and $.44 \%$ variance respectively.

Table 3: Mean, Standard Deviation and t-values for males and females students on Generosity, Spirituality, Resilience and Psychological wellbeing $(\mathrm{N}=175)$

\begin{tabular}{lccccccccc}
\hline \multicolumn{1}{c}{ Female(n= 77) } & \multicolumn{2}{c}{ Male $(\mathbf{n}=\mathbf{9 8})$} & \multicolumn{4}{c}{$\mathbf{9 5 \%} \boldsymbol{C I}$} & Cohen's $\boldsymbol{d}$ \\
\hline Variables & $M$ & $S D$ & $M$ & $S D$ & $t(173)$ & $p$ & $L L$ & $U L$ & \\
\hline Generosity & 29.34 & 6.01 & 23.96 & 5.30 & -8.36 & .00 & -6.96 & -4.03 & 0.95 \\
\hline Spirituality & 24.90 & 3.22 & 24.36 & 3.52 & -1.39 & .87 & -1.61 & .39 & 0.16 \\
\hline Resilience & 32.82 & 5.01 & 23.80 & 6.96 & -10.1 & .00 & -7.45 & -6.70 & 1.49 \\
\hline PWB & 81.01 & 10.29 & 82.52 & 11.29 & -.85 & .59 & -3.55 & 1.73 & 0.14 \\
\hline
\end{tabular}

Note. PWB $=$ Psychological well-being.

In Table $3 t$-test analysis revealed that females had high generosity and more resilience in comparison to male youth but no significant differences are visible in terms of spirituality and psychological well-being.

Table 4: Mean, Standard Deviation and t-values for males and females students on Generosity, Spirituality, Resilience and Psychological wellbeing $(\mathrm{N}=175)$

\begin{tabular}{llllllllll}
\hline & \multicolumn{1}{c}{ Nuclear $(\boldsymbol{n}=\mathbf{8 7})$} & \multicolumn{2}{c}{ Joint $(\boldsymbol{n}=\mathbf{8 8})$} & \multicolumn{4}{c}{$\mathbf{9 5 \%} \boldsymbol{C I}$} & Cohen's $\boldsymbol{d}$ \\
\hline Variables & $M$ & $S D$ & $M$ & $S D$ & $t(173)$ & $p$ & $L L$ & $U L$ & \\
\hline Generosity & 31.44 & 5.41 & 33.46 & 5.36 & -7.96 & .08 & -4.96 & 3.83 & 0.38 \\
\hline Spirituality & 28.20 & 3.02 & 27.16 & 3.22 & -1.37 & .76 & -1.31 & .59 & 0.33 \\
\hline Resilience & 39.46 & 8.62 & 52.92 & 7.72 & 2.62 & .01 & 4.36 & 6.23 & 1.65 \\
\hline PWB & 90.29 & 17.36 & 91.58 & 18.47 & -.33 & .74 & -6.63 & 4.73 & 0.07 \\
\hline
\end{tabular}

Note. PWB = Psychological well-being.

T-test analysis in table 4 shows that youth from the joint family system is participants from the joint families were comparatively more generous and resilient than those from the nuclear families.

\section{DISCUSSION/ANALYSIS}

Present study results represented a significant positive relationship of generosity with spirituality, resilience, and psychological well-being among youth. Linear regression further represented that high generosity was a significant predictor of high spirituality, more resilience, and high psychological wellbeing. These findings confirmed the first hypothesis and are also online with the finding of previous researches. Sablosky (2014) found that generosity is linked with one's positive attitudes towards life and related persons. As the person becomes more and more sharing he/she this ultimately strengthens his/her spiritual and mental well-being. In the evolutionary biological study of cooperation, it is widely accepted that humans cooperate in a wide variety of ways and on large scales (Townsend, Aktipis, Balliet \& Cronk, 2020). The empirical shred of evidence also found that generosity, life-management skills, and social selfefficacy beliefs play an important in promoting ones' goodness towards life in general especially when it comes to their interest and belief in activities for the common good (Van Dyke, et, al., 2009); Koenig, 2012; Choudhry, et al., 2018). As the youth gets more and more involved in interpersonal generosity it fosters their resiliency to combat stressors of life due to the remarkable benefits they earned for attaining spiritual wealth and mental health. The response to a disaster by communities and larger systems can make a difference for individual and family well-being and resilience (Walsh, 2020). Diener and Seligman (2004) also assert that maintaining meaningful ways to connecting others results in improved health both mental and physical level. It also sharpens one's ability to fight the adversities of life. When youth tends to volunteer their time to help others, for example, helping people in a homeless shelter, serving them meals cheerfully and making everyone smile; spends/donate their money for the welfare of the needy; offers their knowledge and skills to teaching in shelter homes or teaching the poor children free of cost this benefits them; they learn to come out of the race of personal interests; think for other human beings which ultimately enhances their spiritual and mental health and they become more and more resilient to combat life stresses. We are relational beings. Recognition of our essential interdependence is vital for our well-being and resilience. In turning to others for help, we can pay it back and pay it forward (Walsh, 2020). Family resilience is fostered by shared beliefs (1) to make meaning of the crisis and challenges; (2) to (re)gain a positive, hopeful outlook that supports active agency, and (3) for transcendence: to rise 
above suffering and hardship through larger values, spiritual beliefs and practices, and experiencing transformations in new priorities, a sense of purpose, and deeper bonds (Walsh, 2020).

The present study also sought some demographic differentiation and t-test analysis revealed that females had high generosity and more resilience but no significant differences were found in terms of spirituality and psychological wellbeing. This partially accepts the present study hypothesis. Literature also reveals that females are more on marginal lines of forgiving others and being more generous as compared to males (Mesch, Rooney, Steinberg, \& Denton, 2006; Vigna, List, Malmendier \& Rao, 2013). Hampel and Petermann (2005) found that female youth use resilience factors such as seeking and getting support more than male youth, similarly, it is also evident from the findings of Sun and Stewart (2014) girls are more resilient and show a greater level of meaningful participation in social activities. According to Rich (2012), non-significant gender differences were found in spirituality. Similar findings were reported by Hafeez and Rafique (2013) that both gender display the same level of spirituality and psychological well-being unlikely the findings given by Maselko and Kubzansky (2006), Joshanloo and Daemi (2015) as well as Piper and Schnepf (2007).

The present study also explored the impact of the family system on the level of generosity, spirituality, resilience, and psychological well-being, and results of t-test analysis revealed that youth from the joint family system is participants from the joint families were comparatively more generous and resilient than those from the nuclear families. Rajeev and Kunjachan (2014) found that in collectivist cultures where traditional norms and values and running; the joint family system is considered the most stronger arena for building generosity, resilience, and coping among youth which also led to empowerment in the families and communities. As per norms of collectivist cultures, it is commonly believed that generosity, life-management skills, and social self-efficacy play an important role in attaining common good on a community basis. However, these findings are in contrast to the findings of Prajapati (2013) who found no significant differences among adolescents of joint and nuclear families.

\section{CONCLUSION}

The study concluded that generosity as an attribute has a significant positive link with youth's spirituality and ultimately buffers their resilience and psychological well-being. Especially youngs are much more generous and resilient. Similarly, this goodness attribute is much more prevalent among youth of joint family setup as they showed a high tendency for being generous towards others and were found to be comparatively more resilient in adverse times than youth of the nuclear families.

\section{LIMITATION AND STUDY FORWARD}

Like any other social science research present study was also not free of limitations. The sample of the study was very limited and many other contributing factors like personality traits, parenting practices, religion, and SES were not included in the study to see their relative impact on the construct under study. All these limitations certainly restrict the generalizability of findings. Therefore, future research should incorporate the above-mentioned elements to achieve a more comprehensive understating of the phenomenon under study.

\section{IMPLICATIONS}

Helping is contagious as acts of generosity and kindness beget more generosity in a chain reaction of goodness. Therefore, cultivating a harmonious and mentally healthy society is much more need of the time to be acted upon the giving principle of all the religions of the world including Islam which teaches us for helping the needy and the ultimate result is spiritual, mental, and psychological health. This study finding will be beneficial for social psychologists and health psychologists for understanding the benefits of generosity and how it will bring progressive changes for the attainment of healthy living communities.

\section{ACKNOWLEDGEMENT}

The author acknowledged the voluntary participation of the study sample. The authors also declare no financial disclosure related to the submission.

\section{DECLARATION OF COMPETING INTEREST}

The authors declare no conflicts of interest.

\section{AUTHORS CONTRIBUTION}

The main idea of research was conceived by Najma Iqbal Malik and also reviewed and finalized paper, both Shahida Perveen and Mehr Mohsin Raza contributed to data collection, data analysis, and literature review. All authors have cowritten and approved the final version of the manuscript.

\section{REFERENCES}

1. Ahrens, C. E., Abeling, S., Ahmad, S., \& Hinman, J. (2010). Spirituality and well-being: The relationship between religious coping and recovery from sexual assault. Journal of Interpersonal Violence, 25(7), 12421263. https://doi.org/10.1177/0886260509340533 
2. Bandura, A. (1982). Self-efficacy mechanisms in human agency. American Psychologist, 37, 122147. https://doi.org/10.1037/0003-066X.37.2.122

3. Bonelli, R. M., \& Koenig, H. G. (2013). Mental disorders, religion and spirituality 1990 to 2010: A systematic evidence-based review. Journal of Religion and Health, 52(2), 657-673. https://doi.org/10.1007/s10943-0139691-4

4. Choudhry, F. R., Khan, T. M., Park, M. S. A., \& Golden, K. J. (2018). Mental health conceptualization and resilience factors in the Kalasha youth: an indigenous ethnic and religious minority community in Pakistan. Frontiers in Public Health, 6, 187. https://doi.org/10.3389/fpubh.2018.00187

5. Connor, K. M., \& Davidson, J. R. (2003). Development of a new resilience scale: The Connor-Davidson Resilience Scale (CD-RISC). Depression and Anxiety, 18(2), 76-82. https://doi.org/10.1002/da.10113

6. Connor, K. M., Davidson, J. R., \& Lee, L. C. (2003). Spirituality, resilience, and anger in survivors of violent trauma: A community survey. Journal of traumatic stress, 16(5), 487-494. https://doi.org/10.1023/A:1025762512279

7. Diener, E., \& Seligman, M. E. P. (2004). Beyond money: Toward an economy of well-being. Psychological Science in the Public Interest, 5, 1-31. https://doi.org/10.1111/j.0963-7214.2004.00501001.x

8. Durrant, R., \& Poppelwell, Z. (2017). Religion, Crime, and Punishment: An Evolutionary Perspective. Pp. 5588. Springer International Publishing. https://doi.org/10.1007/978-3-319-64428-8 3

9. Emmons, R. A. (2000). Spirituality and intelligence: Problems and prospects. The International Journal for the Psychology of Religion, 10(1), 57-64. https://doi.org/10.1207/S15327582IJPR1001_6

10. Hafeez, A. \& Rafique, R. (2013). Spirituality and religiosity as predictors of psychological well-being in residents of old homes. The Dialogue, 8(3), 285-301.

11. Hasan, H., \& Ejaz, N. (2018). Testing for Differences Across Genders: Evidence from Ultimatum Game. The Pakistan Development Review, 57(3), 333-349. https://doi.org/10.30541/v57i3pp.333-349

12. Hampel, P., \& Petermann, F. (2005). Age and gender effects on coping in children and adolescents. Journal of Youth and Adolescence, 34(2), 73-83. https://doi.org/10.1007/s10964-005-3207-9

13. James, A. G., \& Mark A. F. (2015). Relations between youths' conceptions of spirituality and their developmental outcomes. Journal of Adolescence, 43, 171-80. https://doi.org/10.1016/j.adolescence.2015.05.014

14. Joshanloo, M. \& Daemi, F. (2015). Self-esteem mediates the relationship between spirituality and subjective well-being in Iran. International Journal of Psychology, 50(2), 115-120. https://doi.org/10.1002/ijop.12061

15. King, M., Marston, L., McManus, S., Brugha, T., Meltzer, H., \& Bebbington, P. (2013). Religion, spirituality and mental health: Results from a national study of English households. The British Journal of Psychiatry, 202(1), 68-73. https://doi.org/10.1192/bjp.bp.112.112003

16. Koenig H. G. (2012). Religion, spirituality, and health: the research and clinical implications. ISRN Psychiatry, 2012, 278730. https://doi.org/10.5402/2012/278730

17. Koenig, H. G., McCullough, M. E., \& Larson, D. B. (2001). Handbook of religion and health. New York, New York: Oxford University Press. https://doi.org/10.1093/acprof:oso/9780195118667.001.0001

18. Koenig, L. B., \& Vaillant, G. E. (2009). A prospective study of church attendance and health over the lifespan. Health Psychology, 28(1), 117-124. https://doi.org/10.1037/a0012984

19. Laurent, B., Nazareth, I., Bellon-Saame' no, J., Geerlings, M. I., Maaroos, H., Saldivia, S., . . King, M. (2013). Spiritual and religious beliefs as risk factors for the onset of major depression: An international cohort study. Psychological Medicine, 43(10), 2109-20.

20. Lucchetti G., Lucchetti A. L., Peres M. F., Moreira-Almeida A., Koenig H. G. (2012). Religiousness, health, and depression in older adults from a brazilian military setting. ISRN Psychiatry.

21. Maselko, J., \& Kubzansky, L. D. (2006). Gender differences in religious practices, spiritual experiences, and health: results from the US General Social Survey. Social Science and Medicine, 62(11), 2848-2860. https://doi.org/10.1016/j.socscimed.2005.11.008

22. McCaffrey, A. M., Eisenberg, D. M., Legedza, A. T. R., Davis, R. B., \& Phillips, R. S. (2004). Prayer for health concerns. Archives of Internal Medicine, 164, 858-862. https://doi.org/10.1001/archinte.164.8.858

23. McIntosh, D. N., Poulin, M. J., Silver, R. C., \& Holman, E. A. (2011). The distinct roles of spirituality and religiosity in physical and mental health after collective trauma: A national longitudinal study of responses to the 9/11 attacks. Journal of Behavioral Medicine, 34(6), 497-507. https://doi.org/10.1007/s10865-011-9331-y

24. Mesch, D. J., Rooney, P. M., Steinberg, K. S. \& Denton, B. (2006). The effects of race, gender, and marital status on giving and volunteering in Indiana, Nonprofit and Voluntary Sector Quarterly, 35 (4), 565-587. https://doi.org/10.1177/0899764006288288

25. Miller, W. R., \& Thoresen, C. E. (2003). Spirituality, religion, and health: An emerging research field. American Psychologist, 58(1), 24-35. https://doi.org/10.1037/0003-066X.58.1.24

26. Peterson, C., \& Seligman, M. E. P. (2004). Character strengths and virtues: A handbook and classification. Oxford, United Kingdom: Oxford University Press

27. Piper, G., \& Schnepf, S. V. (2007). Gender differences in charitable giving. Discussion Paper No. 3242. The Institute for the Study of Labor (IZA), Germany. 
28. Prajapati, R. O. (2013). The psychological well-being among joint and nuclear families: A comparative study. The International Journal of Indian Psychology, 01(01), 47-53. https://doi.org/10.25215/0101.005

29. Rajeev, S. P., \& Kunjachan, D. (2014). Building family resilience: A social work approach. International Journal of Social Work and Human Services, 2(6), 250-255.

30. Rich, A. (2012). Gender and spirituality: Are women more spiritual? Unpublished Honors Program dissertation, Liberty University.

31. Ruffle, B. J., \& Sosis, R. (2006). Cooperation and the in-group-out-group bias: A field test on Israeli kibbutz members and city residents. Journal of Economic Behavior and Organization, 60 (2),147-163. https://doi.org/10.1016/j.jebo.2004.07.007

32. Ryff, C., \& Keyes, C. (1995). The structure of psychological well-being revisited. Journal of Personality and Social Psychology, 69, 719-727. https://doi.org/10.1037/0022-3514.69.4.719

33. Sablosky, R. (2014). Does Religion Foster Generosity? The Social Science Journal, 51(4). Atlanta: Elsevier Inc. https://doi.org/10.1016/j.soscij.2014.03.012

34. Seybold, K. S., \& Hill, P. C. (2001). The role of religion and spirituality in mental and physical health. Current Directions in Psychological Science, 10(1), 21-24. https://doi.org/10.1111/1467-8721.00106

35. Shaheen, F. (2016). A study of spirituality and social support in relation to depression among adolescents. Indian Journal of Positive Psychology, 7(2), 181-186.

36. Smith, C., \& Hill, J. P. (2009). Toward the measurement of interpersonal generosity (IG): An IG scale conceptualized, tested, and validated. http://generosityresearch.nd.edu/assets/13798/ig paper_smith_hill_rev.pdf

37. Sternthal, M. J., Williams, D. R., Musick, M. A., \& Buck, A. C. (2010). Depression, anxiety, and religious life: A search for mediators. Journal of Health and Social Behavior, 51(3), 343- 359. https://doi.org/10.1177/0022146510378237

38. Southwick, S. M., Sippel, L., Krystal, J., Charney, D., Mayes, L., \& Pietrzak, R. (2016). Why are some individuals more resilient than others: the role of social support. World Psychiatry, 15(1), 77. https://doi.org/10.1002/wps.20282

39. Sun, J. \& Stewart, D. (2014). Age and gender effects on resilience in children and adolescents. School of Public Health, Logan Campus, Griffith University, University Drive, Meadowbrook, Queensland 4131, Australia.

40. Townsend, C., Aktipis, A. Balliet, D., Cronk, L. (2020). Generosity among the Ik of Uganda. Evolutionary Human Sciences, 2(23), 1-13. https://doi.org/10.1017/ehs.2020.22

41. Van Dyke, C. J., Glenwick, D. S., Cecero, J. J., \& Kim, S. K. (2009). The relationship of religious coping and spirituality to adjustment and psychological distress in urban early adolescents. Mental Health, Religion, and Culture, 12(4), 369-383. https://doi.org/10.1080/13674670902737723

42. Vigna, S. D., List, J. A., Malmendier, U., \& Rao, G. (2013). The importance of being marginal: Gender differences in generosity. Working Paper 18748 by National Bureau of Economic Research,1050 Massachusetts Avenue, Cambridge, MA 02138.

43. Vinayak, S., \& Judge, J. (2018). Resilience and empathy as predictors of psychological wellbeing among adolescents. International Journal of Health Sciences and Research, 8(4), 192-200.

44. Wilson, J. A. (1956). The Culture of Ancient Egypt. University of Chicago Press, Chicago. https://doi.org/10.7208/chicago/9780226148229.001.0001

45. Walsh, F. (2020). Loss and resilience in the time of COVID-19: Meaning-making, hope, and transcendence. Family Process, 59(3), 898-911. https://doi.org/10.1111/famp.12588 